
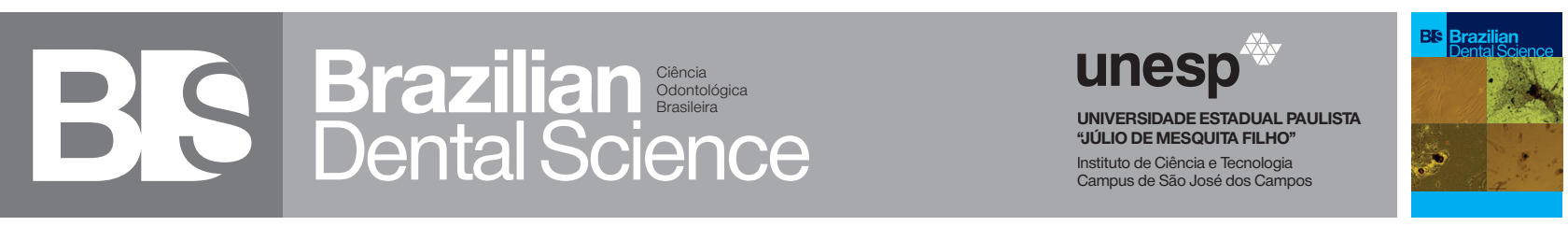

\title{
Fracture load of nano-ceramic composite material for anterior endocrown restorations
}

\author{
Carga de fratura de material compósito nano-cerâmico para restaurações endocrown anteriores \\ Salma ALGHALAYINI ${ }^{1}$, Kamal EBEID ${ }^{1}$, Ayman ALDAHRAB ${ }^{2}$, Marwa WAHSH ${ }^{1}$ \\ 1 - Department of Fixed Prosthodontics - Faculty of Dentistry - Ain Shams University - Egypt. \\ 2 - Department of Prosthodontics - King Abdulaziz University - Jeddah - KSA.
}

\begin{abstract}
Objective: to evaluate ability of Nano Ceramic Composite endocrown to withstand occlusal forces when used in the anterior region. Material and Methods: eighty endodontically treated maxillary central incisors teeth were randomly divided into two main groups according to the restoration type. Forty of these teeth were post, core and crown restorations and 40 were endocrown restorations. Then they were divided by halves into two subgroups according to the material used 20 were made with Lava Ultimate and the other 20 with IPS e.max. Each subgroup was then further subdivided into two divisions according to the remaining tooth structure above the CEJ ( $\mathrm{n}$ = 10): $2 \mathrm{~mm}$ and $0.5 \mathrm{~mm}$ above the CEJ. After teeth preparation, the restorations were all made by CAD/CAM system (Cerec MCXL). All samples had undergone cyclic fatigue testing, and then loaded to fracture using a universal testing machine. The specimens were measured and statistically analyzed using Mann-Whitney test for comparing the mean changes between the groups. Results: Lava Ultimate showed higher mean fracture load values than IPS e.max specimens. Conclusions: endocrowns were found to be more favorable when used on endodontically treated teeth than the conventional post, core and crown restorations.
\end{abstract}

\section{KEYWORDS}

Endocrowns; All-Ceramic; Fracture; Cyclic loading.

\section{RESUMO}

Objetivo: Avaliar a capacidade do compósito nanocerâmico endocrown para suportar forças oclusais quando usado na região anterior. Material e Métodos: Oitenta incisivos centrais superiores tratados endodonticamente foram divididos aleatoriamente em dois grupos principais, de acordo com o tipo de restauração. Quarenta desses dentes receberam restaurações com retentor intrarradicular, núcleo e coroa e 40 receberam restaurações endocrown. Em seguida, foram divididos pela metade em dois subgrupos, de acordo com o material utilizado, sendo 20 confeccionados com Lava Ultimate e os demais 20 com IPS e.max. Cada subgrupo foi posteriormente subdividido em dois, de acordo com a estrutura dentária remanescente acima da JEC ( $\mathrm{n}=$ 10): $2 \mathrm{~mm}$ e $0,5 \mathrm{~mm}$ acima do JEC. Após o preparo dos dentes, todas as restaurações foram realizadas pelo sistema CAD/ CAM (Cerec MCXL). Todas as amostras foram submetidas a testes de fadiga cíclica e submetidas ao esforço até a fratura em uma máquina universal de testes. As amostras foram medidas e analisadas estatisticamente pelo teste de MannWhitney para comparação das alterações médias entre os grupos. Resultados: lava Ultimate apresentaram valores médios mais altos de carga até a fratura do que as amostras IPS e.max. Conclusões: as endocrowns mostraram-se mais favoráveis quando utilizadas em dentes tratados endodonticamente do que as restaurações convencionais com retentor intrarradicular, núcleo e coroa.

\section{PALAVRAS-CHAVE}

Endocrowns; Cerâmica; Fratura; Ciclagem mecânica. 


\section{INTRODUCTION}

$\mathrm{T}$ he selection of the best restoration for an endodontically treated tooth in the esthetic zone depends on strength and the ability to recreate the form, function, and esthetics of the natural tooth. The conventional means of restoring endodontically treated teeth is a build-up with post and core, and placement of a full coverage crown with sufficient ferrule [1]. It was believed that a dowel can strengthens the remaining weak tooth structure but opinion has since changed, rejecting that concept and proving that its main purpose has been the stabilization of the remaining tooth structure and the replacement of the missing part [2].

A completely different newer approach recommends the use of the so-called endocrown instead of post and core. This technique reserves the maximum tooth structure, reduces the need for macro-retentive geometry, provides more efficient and esthetic results and decreases the interfaces which decrease the microleakage and enhance the prognosis. It also avoids additional weakening of the tooth by a post-space preparation and procedural errors such as root perforation [2].

Conservative approach is highly needed since the oral cavity is a very challenging environment due to cyclic loading and the placement of the anterior teeth at an angle to the occlusal plane, creating oblique forces which are considered the most destructive type of forces [3]. The development of computer aided design/computer aided manufacturing (CAD/CAM) systems and software offer several advantages in clinical practice $[4,5]$. One of the materials used with CAD/CAM is lithium disilicate glass ceramic blocks, which is an improved glass-ceramic material with a relatively high fracture strength and optimum esthetics [6]. Another material also used with $\mathrm{CAD} / \mathrm{CAM}$ is resin nanoceramic blocks (RNC). These blocks are supposed to perform similar to or even better than glass ceramic materials in regards to mechanical and wear performance, durability and esthetics. They are claimed to be resilient and shock absorbent, easy to adjust and even allow adding-on with light cured restorative to give the dentist the ability to achieve perfect occlusion [7].

Thus, the aim of this study was to evaluate the fracture load of anterior teeth restored with anterior endocrowns in comparison to those restored with post, core and crown using two materials either lithium disilicate or nano ceramic composite.

\section{MATERIAL AND METHODS}

Eighty recently extracted human upper central incisors that were free of caries, attrition, abrasion, cracking or previous restoration were selected, cleaned under tap water, debrided from all soft tissues or bone and stored in $0.1 \%$ thymol supersaturated solution at $4^{\circ} \mathrm{C}$ before preparation. Teeth of similar size and shape were selected by root length and crown dimensions. The roots were measured from the cemento-enamel junction (CEJ) to the apex facially and were within the range of $15 \pm 1$ $\mathrm{mm}$. The crowns dimensions were $10 \pm 1 \mathrm{~mm}$ inciso-cervically, $6 \pm 1 \mathrm{~mm}$ labiolingually and $8 \pm 1 \mathrm{~mm}$ mesiodistally dimension.

Canal morphology was verified from standardized apical radiographs both in the buccolingual and mesiodistal directions to ensure there was no internal resorption or canal abnormality. Teeth were endodontically treated by the same operator for standardization. All the teeth lengths were in the average of $25 \pm$ $1 \mathrm{~mm}$ range measured from the incisal edge till the apex.

The endodontically treated teeth were randomly divided into two main groups, according to restoration type $(n=40)$, Group 1 ; post, core and crown restoration (control group) and group 2; endocrown restoration. These two main group were then subdivided, according to the material used for the restoration, into two subgroups $(n-=20)$. Subgroup A; IPS e.max (Ivoclar, Schaan, Liechtenstein) and subgroup B; Lava Ultimate (3M ESPE, St. Paul, 
USA). Each subgroup was further split into two divisions $(\mathrm{n}=10)$, according to the remaining tooth structure above the CEJ mesially. These divisions were: Division I; $0.5 \mathrm{~mm}$ remaining tooth structure above the CEJ. Division II; 2 $\mathrm{mm}$ remaining tooth structure above the CEJ.

\section{Sample preparation}

After root canal treatment, the crowns of the teeth were cut horizontally using a diamond stone mounted on a high-speed hand piece with copious amount of water to avoid cracking. Each cut was according to the amount of remaining tooth structure in respect to its division grouping $(0.5 \mathrm{~mm}$ or $2 \mathrm{~mm}$ above the CEJ). Both divisions were measured at the highest point of the curvature of the cervical line, which is the peak of the mesial proximal surface.

Teeth in group 1: underwent post and core preparation. The RelyX Fiber Post (3M ESPE) and drills were used. The depth of the post space was drilled, leaving $5 \mathrm{~mm}$ of gutta percha apically to preserve the apical seal. Posts were cemented with RelyX Unicem Cement (3M ESPE). The composite restoration cores were bonded using Single Bond Universal Adhesive (3M ESPE), a single L-Pop ${ }^{\mathrm{TM}}$ unit dose delivery was used with every single tooth and standardized incremental composite build-up technique was employed. A resin crown former was used for facilitation and standardization of building up of all the cores with $5 \mathrm{~mm}$ height.

The teeth were then prepared by hand by the same operator under water spray. The margins were designed $0.5 \mathrm{~mm}$ or $2 \mathrm{~mm}$ above the CEJ and $1 \mathrm{~mm}$ in width with a rounded shoulder finish line as shown in figure 1 . After the preparation of five teeth the bur was discarded and replaced. In group 2: the endocrwons intracanal preparation in was 5 $\mathrm{mm}$ in depth into the root canal from CEJ as a reference point, as shown in figure 2 .

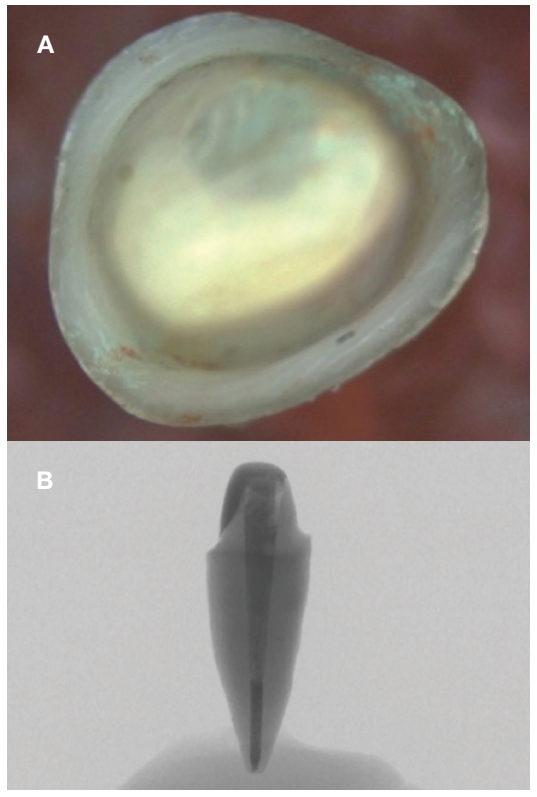

Figure 1- (A and B): Post, core, and crown preparation.

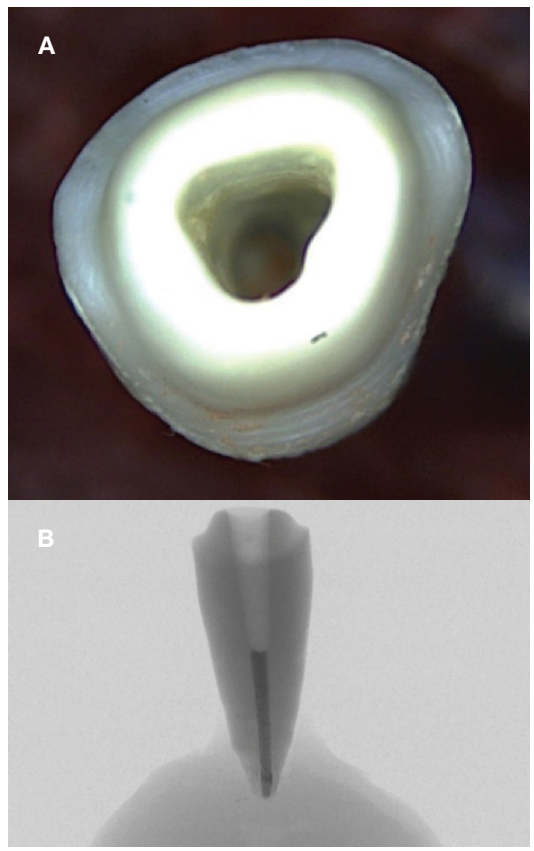

Figure 2 - (A and B): Endocrown showing intracanal preparation.

The crowns and endocrowns of all the specimens were fabricated with CEREC system (Sirona, Bensheim, Germany). CEREC OmniCam was used for scanning the preparation, the CEREC software version 4.4 for restoration design and the CEREC MC XL milling unit for restoration fabrication. The computer database 
was used to select the available design and set the cement space to be 70 microns.

The proposed restoration was right central incisor with $10 \mathrm{~mm}$ in length from the incisal edge till the CEJ. The computer then calculated the shape (CAD) then guided the milling machine (CAM) to mill the restorations. The block size was C14L for the Lava Ultimate (3M ESPE) and C14 for the IPS e.max (Ivoclar).

IPS e.max CAD Crystal/glaze paste (Ivoclar) was used to glaze the IPS e.max specimens. Polishing of Lava-Ultimate restorations were done with a rubber tool and VH Technologies Diashine Fine Soft Extra Oral Polishing Paste (Ultradent, USA).

The restorations were cemented using RelyX Ultimate. IPS e.max specimens were etched by hydrofluoric acid (VITA, Germany) for 20 seconds, then rinsed thoroughly with water for 15 seconds, dried with air stream, silanated for 1 minute, and then dried again with oil-free air for 10 seconds. As for the Lava Ultimate, the fitting surface was abraded using $\mathrm{Al}_{2} \mathrm{O}_{3}$ particles at 2 bars pressure then a layer of Single Bond Universal Adhesive was applied.

All teeth were etched with phosphoric acid (Ultradent, USA) and the same adhesive and cement were applied on the tooth surface to wet the entire surfaces. The restorations were then seated and stabilized by finger pressure long enough for the cement to full set.

Each tooth was vertically mounted by using a parallel device in self cure acrylic resin (Acrostone, WHW Plastics, East Yorkshire, UK) in customized molds for orienting the tooth's long axis to be perpendicular to the horizontal plane. The crowns of the teeth remained free of the acrylic resin, and the roots were covered to the height of $2 \mathrm{~mm}$ below the CEJ. The roots of the teeth were covered with a thin layer of utility wax approximately 0.2 $\mathrm{mm}$ by dipping technique, which were replaced by Impregum silicone impression material resin (3M ESPE) in order to simulate the periodontal ligaments. During the course of polymerization, the acrylic block was cooled in water to avoid the dentine dehydration.

All samples were individually mounted onto the lower fixed compartment of a computercontrolled testing machine (Electropulse E300; Instron Instruments Ltd., USA). The samples underwent cyclic loading by means of metallic sphere of $4 \mathrm{~mm}$ diameter, which was attached to the upper movable compartment of the machine. The load was applied at inclined 130 degrees angle just above the cingulum on the palatal surface.

Load profile was in the form of sine wave at the rate (frequency) of $10,000 \mathrm{~Hz}$. The load was cycled between maximum of $100 \mathrm{~N}$ and minimum of $20 \mathrm{~N}$. Without reaching zero to avoid lateral dislocation of the loading tip and help in stabilizing of specimen during the test. The cyclic loading consisted of 50,000 cycles, and then the specimens were examined under $10 \mathrm{X}$ magnification in a stereomicroscope to detect any cracks and surface flaws. The specimens were further loaded for another 50,000 cycles and rechecked under the microscope to detect any increase in the cracks size or length (total of 100.00 cycles). The same machine was used to apply the compressive static load. A stainless steel bar was fixed vertically in the testing machine to apply the load on the palatal surface just above the cingulum at a 130-degree angle. And constant compressive load was applied at a crosshead speed of $1 \mathrm{~mm} / \mathrm{min}$ until failure occurred. The force at failure was measured in newton.

The CEJ was considered the reference line to evaluate mode of failure. Any fracture above it was considered restorable and any fracture below it was considered non restorable. The inspection was done by direct vision and the restorability was coded as follows: (0) Restorable and (1) Non restorable.

\section{Statistical analysis}

Quantitative measured variables were described by the Mean, Standard Deviation (SD), while qualitative categorical variables were described by frequency and percentages. Independent sample t-test, Mann and Whitney U test were used for comparing the mean changes between any two groups. Significance level was considered at $\mathrm{P}<0.05, \mathrm{P}<0.01$ was considered highly significant, while $\mathrm{P}>0.05$ was considered non-significant. Two tailed tests are assumed throughout the analysis for all statistical tests.

\section{RESULTS}

Group 1 showed a higher rate of crack per unit than group 2. Also division II showed a higher rate when compared to division I. Cracks are shown in figure 3 . But the material was the main influencing factor in crack formation, the IPS e.max showed higher crack number in comparison so the Lava Ultimate that experienced almost zero cracks as shown in figure 4 . 


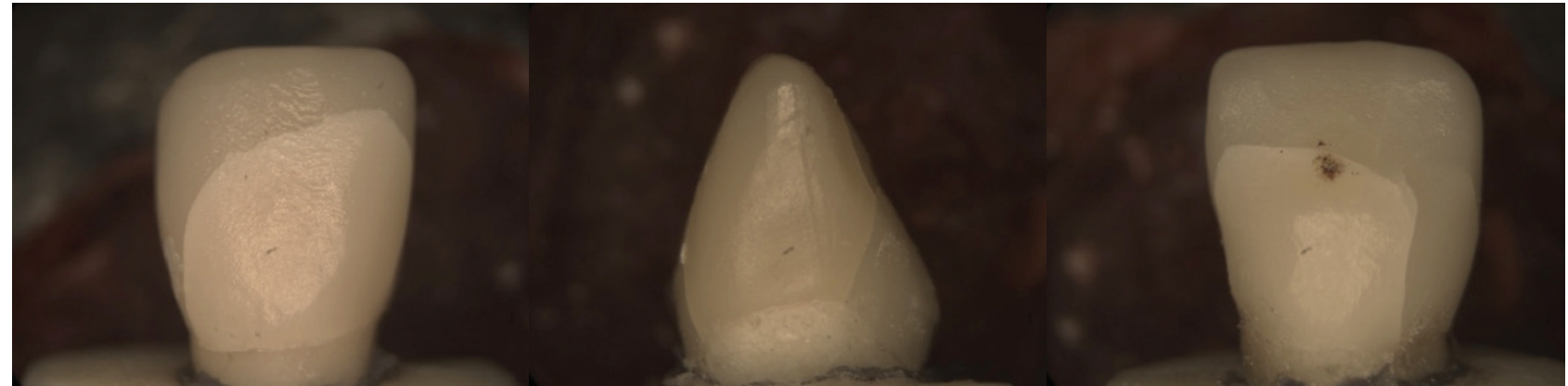

Figure 3: Cracks shown in crown.

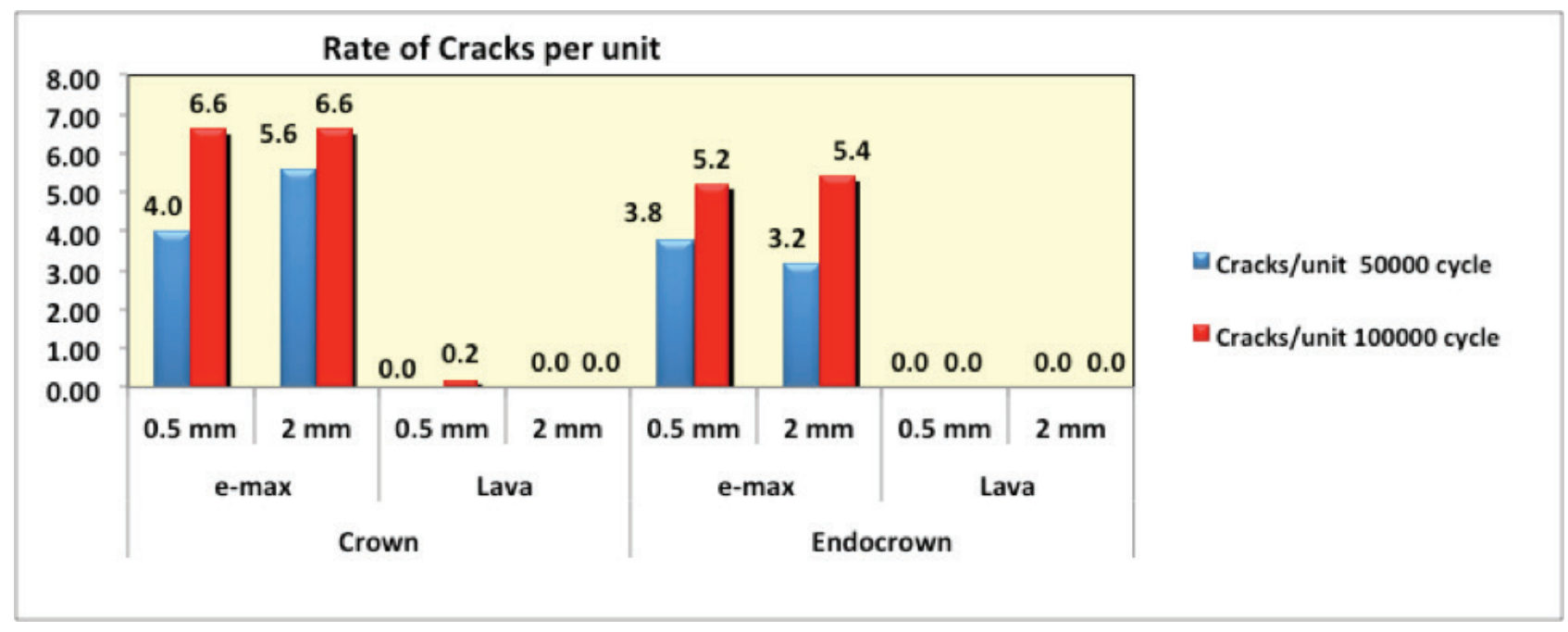

Figure 4: Rate of crack per unit for all subgroups.

After static load was applied, the failure occurred and was measured in newton. Both the restoration technique and the preparation design were statistically non-significant ( $p$ $>0.05$ ). Only the material type was highly significant in the fracture load ( $p<0.01)$, the Lava Ultimate had higher fracture load values than the IPS e.max specimens as seen in figure 5 .

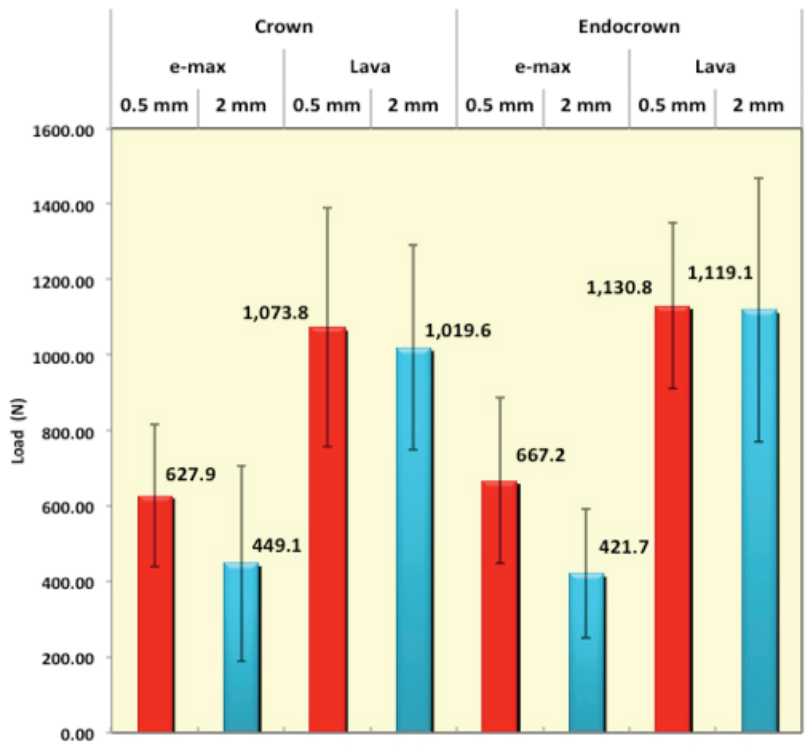

Figure 5: Fracture load in Newtons for all subgroups. 
Comparing restoration techniques, teeth were considered restorable if the fracture did not extend beyond the cemento-enamel junctions. The endocrowns were more restorable than crowns also, IPS e.max specimens were more restorable than Lava Ultimate. Those specimens with shorter $0.5 \mathrm{~mm}$ preparation were more restorable than the ones with remaining $2 \mathrm{~mm}$ tooth structure. Lava Ultimate crowns with $2 \mathrm{~mm}$ preparations had the worst restorability potential. On the other hand, IPS e.max endocrowns with $2 \mathrm{~mm}$ preparations had the best restorability potential. The restorability percentage is demonstrated in figure 6 .

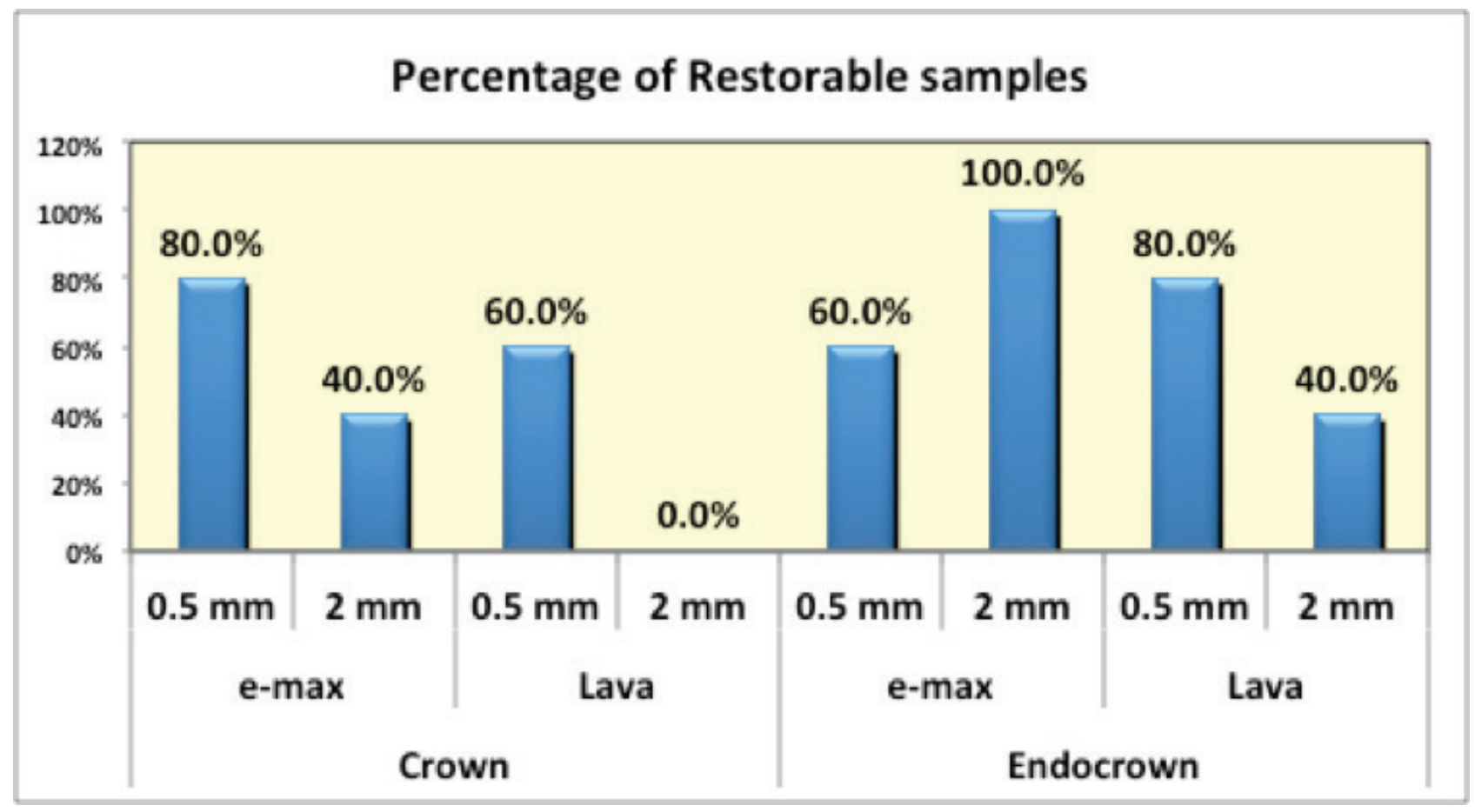

Figure 6: Restorability potential for all subgroups.

\section{DISCUSSION}

New technologies and materials are routinely introduced into dental practice [8]. Different restorative techniques, materials and preparations were used in this current study with some comparisons in an attempt for a better understanding of recent choices available in restoring endodontically treated teeth.

This study had focused on the anterior esthetic zone and in particular maxillary central incisors so the teeth would have more or less the same dimensions. Collecting sound extracted teeth can be a challenge when standardization is of value. The teeth collected needed to be sound with a very small variation in size and shape, thus the limited number of specimens in our study [9].

Endocrown restorations are not commonly used in the anterior area, so this study was designed to study anterior endocrowns by comparing it to the conventional post-corecrown restorations routinely used in non-vital teeth. Moreover, the endocrown comprises a circumferential butt margin and a central retention cavity inside the pulp chamber which constructs both the crown and core as a single unit. Preparation of endocrowns in this study had some modifications. Since esthetics is the prime concern, a normal rounded shoulder finish line was placed $0.5 \mathrm{~mm}$ above the CEJ 
instead of the butt margin preparation. Also due to the absence of a pulp chamber in the anterior teeth, the preparation was extended deeper into the root canal for retention. This extension was verified by the use of a scaled periodontal probe [9].

Ceramics and composite resins are the two main groups of CAD/CAM restorative materials. Since the aim of this study was to evaluate the innovative RCN material (Lava Ultimate in particular), it was compared to an improved glass ceramic material (IPS e.max).

As claimed by the manufacturer, Lava Ultimate has high fracture toughness $(>2.0$ $\mathrm{MPa} \mathrm{m}^{0.5}$ ), flexural strength ( $\left.>200 \mathrm{MPa}\right)$, resiliency $(<12 \mathrm{GPa}$ ) and doesn't need firing. It is composed of zirconia/silica nanoceramic particles embedded in a highly cross-linked resin matrix. While e.max CAD is a lithium disilicate glass ceramic with flexural strength of $>300 \mathrm{MPa}$, fracture toughness of $>2.0$ $\mathrm{MPa} \mathrm{m}^{0.5}$ and resiliency of $>90 \mathrm{GPa}[10,11]$.

The aim of this study was to investigate the mechanical behavior and crack formation of the brittle ceramic material so using a load for cementation can create internal or invisible cracks. Therefore, finger pressure was used as many other recent studies with ceramic restorations which also simulates the clinical condition [12].

Before testing, all specimens were embedded in auto polymerizing acrylic resin mold for with silicone-base impression material to simulate the periodontal ligaments. The shock absorbing layer around the roots of the teeth allowed some movement which resembles the normal clinical condition, especially during dynamic and static loading $[13,14]$.

Specimens were loaded with $100 \mathrm{~N}$, which is the load commonly used in previous studies [7]. The mean masticatory forces during mastication and swallowing in humans have been reported to be approximately 40N [14]. A loading angle of 130 degrees was chosen to simulate a contact angle found in class I occlusions between maxillary and mandibular anterior teeth. However, submitting specimens to cyclic loading and then establishing their reaction to fatigue more accurately simulates intraoral conditions than increasing a single load until fracture which was documented in several other studies $[15,16]$.

Lin et al. reported that, according to compressive fracture test results, the final strength exhibited insignificant differences among the endocrown and crown restorations which is in agreement with results of our study. [9] Other in vitro studies by Chang et al and Biacchi and Basting [17,18] showed significantly higher fracture strength for endocrowns when compared with conventional crowns. In vivo study done by Otto et al. [19] had also demonstrated the favorable performance of endocrown restorations, proving that endocrowns performs just as good as crowns.

According to restorability, teeth with fractures below CEJ were considered nonrestorable and can't be retreated using the same restorative technique [20]. In the current study, endocrowns specimens were more restorable. Stress concentrates in the interfaces leading to failure, endocrowns had less interfaces and better mode of failure. Zarone et al. [21] reported that stress concentration in maxillary central incisors restored with an endocrown is at the interface according to 3D finite element analysis. The interfaces of materials with different elastic moduli result in a weak point of restorative system, because of stiffness mismatch of different material influences the stress distribution. This conclusion coincides and explains the results of this study. Similarly, another study stated that according to the failure probability results, the endocrown and conventional crown obtained similar performance, which again agrees with the current study [9].

Another study was in agreement with this current one by Duan et al. [7] it was concluded from it that Lava Ultimate specimens tend to 
have higher or equal failure load compared to CAD/CAM ceramic specimens when tested under loading. This was probably caused by the low stiffness of the Lava Ultimate material acting to reduce the maximum stress level.

Our study was not in agreement with the study performed by Bankoglu Gungor et al. [22] where they compared anterior endocrowns with same crown dimensions made from e.max and Lava Ultimate. They found no difference in fracture strength between the two materials. However, in their study they did not subject the specimens to cyclic loading.

Most of the fractures involving the root imply that a significant amount of force was transmitted to the root [17]. Therefore, Lava Ultimate specimens' mode of failure, in this study, was more catastrophic and less restorable than the IPS e.max specimens. Since higher load for fracture was needed to failure due to less cracking of the Lava Ultimate specimens. This might be attributed to the higher elasticity of Lava Ultimate. The brittle IPS e.max restorations had higher surface cracks, low fracture resistance but better restorability and mode of failure because of less load transmission to the roots.

Regarding the effect of the preparation designs, Sorenson et al. [23] showed that the amount of residual axial tooth structure at the crown margin was found not significant in resisting fracture and that the most critical step in the tooth preparation is the parallel walls of the dentin coronal to the shoulder of the preparation. This could explain the results of this study. Lin et al. [9] proved that restored endodontically treated teeth that do not have complete circumferential tooth structure between the core and preparation finish line, the location of the remaining coronal tooth structure may affect their fracture resistance more than the amount of the remaining tooth structure. When the forces are in a palatal direction, the presence of enough tooth structure labially is more reliable in fracture resistance than the presence of a continuous ferrule all around the tooth at the crown margin was found not significant in resisting fracture and that the most critical step in the tooth preparation is the parallel walls of the dentin coronal to the shoulder of the preparation. This could explain the results of this study.

\section{CONCLUSION}

The material type was the influencing factor in crack formation, fracture resistance and mode of failure. The resilient RNC material had less surface failure and need higher values of load for fracture thus leading to a more catastrophic failure and less restorability. The endocrown restoration seems like a reliable alternative to the conventional methods of restoring root canal treated anterior teeth and Lava Ultimate has several mechanical advantages due to it resiliency.

\section{Acknowledgement}

The authors wish to express appreciation for technical assistance and laboratory support of Dr. Bassem Alturki, Health affairs of Madinah region, Ministry of Health, Saudi Arabia, and Fahd Alsadi, Faculty of Dentistry, King Abdulaziz University, KSA.

\section{REFERENCES}

1. Trushkowsky RD. Esthetic and functional consideration in restoring endodontically treated teeth. Dent Clin North Am. 2011 Apr;55(2):403-10, x. doi: 10.1016/j.cden.2011.01.009.

2. Stricker EJ,Göhring TN. Influence of different posts and cores on marginal adaptation, fracture resistance, and fracture mode of composite resin crowns on human mandibular premolars. An in vitro study. J Dent. 2006 May;34(5):326-35. Epub20050ct3. doi:10.1016/j.jdent.2005.07.007

3. Kurthukoti AJ1, Paul J, Gandhi K, Rao DB. Fracture resistance of endodontically treated permanent anterior teeth restored with three different esthetic post systems: An in vitro study. J Indian Soc Pedod Prev Dent. 20150ctDec;33(4):296-301. doi:10.4103/0970-4388.165675.

4. Falcão Spina DR, Goulart da Costa R, Farias IC, da Cunha LG, Ritter AV, Gonzaga CC,Correr GM.CAD/CAM post-and-core using different esthetic materials: Fracture resistance and bond strengths. Am J Dent. 2017.30(6): 299-304.

5. EgilmezF,Ergun G, Cekic-Nagas I, Vallittu PK, Lassila LVJ.Comparative color and surface parameters of current esthetic restorative CAD/CAM materials. J Adv Prosthodont. 2018 Feb;10(1):32-42. doi: 10.4047/jap.2018101.32. Epub 2018 Feb 12. 
6. Chen C, Trindade FZ de Jager N, Kleverlaan CJ, Feilzer AJJ The fracture resistance of a CAD/CAM Resin Nano Ceramic (RNC) and a CAD ceramic at different thicknesses. Dent Mater.2014 Sep;30(9):954-62. doi: 10.1016/j. dental.2014.05.018. Epub 2014 Jul 15.

7. Duan Y,Griggs JA. Effect of elasticity on stress distribution in CAD/CAM dental crowns: Glass ceramic vs. polymer-matrix composite. JDent. 2015 Jun;43(6)::742-9. doi: 10.1016/j.jdent.2015.01.008. Epub 2015 Jan24.

8. Wittneben JG, Gavric J3, Belser UC, Bornstein MM, Joda T, Chappuis V, Sailer I, Brägger U. Esthetic and Clinical Performance of Implant-Supported AllCeramic Crowns Made with Prefabricated or CAD/CAM Zirconia Abutments: A Randomized, Multicenter Clinical Trial. J Dent Res. 2017 Feb;96(2):163-170. doi: 10.1177/0022034516681767. Epub2016 Dec 7.

9. Lin CL1, Chang YH, Pai CA. Evaluation of failure risks in ceramic restorations for endodontically treated premolar with MOD preparation. Dent Mater. 2011 May;27(5):431-8. doi: 10.1016/j.dental.2010.10.026. Epub 2011Jan 12.

10. ElsakaSE. Bond strength of novelCAD/CAM restorative materials to selfadhesive resin cement: the effect of surface treatments. J Adhes Dent. 2014 Dec;16(6):531-40. doi: 10.3290/j.jad.a33198.

11. Fasbinder DJ, Neiva GF.Surface Evaluation of Polishing Techniques for New ResilientCAD/CAM Restorative Materials. J Esthet Restor Dent. 2016 JanFeb;28(1):56-66. doi:10.1111/jerd.12174. Epub 2015 Jul 14.

12. Attia A, Abdelaziz KM, Freitag S, Kern M. Fracture load of composite resin and feldspathic all-ceramic CAD/CAM crowns. J Prosthet Dent. 2006.95(2): 117-23.

13. Soares PV, Santos-Filho PCF, QueirozEC, Araújo TC, Campos RE, AraújoCA, Soares CJ. Fracture resistance and stress distribution in endodontically treated maxillary premolars restored with composite resin. J Prosthodont. 2008 Feb;17(2):114-119. doi: 10.1111/.1532-849X.2007.00258.x. Epub 2007 0ct30.

14. Akkayan B, Gülmez T. Resistance to fracture of endodontically treated teeth restored with different post systems. J Prosthet Dent. 2002. 87(4): 431-7.doi. 10.1067/mpr.2002.123227.

15. Xible AA, de Jesus Tavarez RR, de Araujo Cdos R, Conti PC, Bonachella WC. Effect of cyclic loading on fracture strength of endodontically treated teeth restored with conventional and esthetic posts. J Appl Oral Sci. 2006. 14(4): 297-303. doi:10.1590/s1678-77572006000400016.
16. Heydecke G, ButzF,Hussein A, Strub JR. Fracture strength after dynamic loading of endodontically treated teeth restored with different post-and-core systems. JProsthet Dent. 2002. 87(4): 438-45. doi: 10.1067/mpr.2002.123849

17. Chang $\mathrm{C}-\mathrm{Y}, \mathrm{Kuo} \mathrm{J}-\mathrm{S}$, Lin Y-S, Chang Y-H. Fracture resistance and failure modes of CEREC endo-crowns and conventional post and core-supported CEREC crowns. Journal of Dental Sciences. 2009.4(3): 110-117.doi: 10.1016/S19917902(09)60016-7

18. Biacchi GR, Basting RT. Comparison of fracture strength of endocrowns and glass fiber post-retained conventional crowns. Oper Dent. 2012 MarApr;37(2):130-6. do: 10.2341/11-105-L. Epub2011Sep 26.

19. Otto T.Computer-aided directall-ceramic crowns: preliminary 1-year results of a prospective clinical study. Int J Periodontics Restorative Dent. 2004 0ct:24(5):446-55.

20. Jirathanyanatt T, Suksaphar W, Banomyong D, Ngoenwiwatkul Y. Endodontically treated posterior teeth restored with or without crown restorations: A5-year retrospective study of survival rates from fracture. J Investig Clin Dent. 2019 Jun 12:e12426. doi:10.111//jicd.12426.

21. ZaroneF, Sorrentino R, Apicella D, Valentino B, Ferrari M, Aversa R, Apicella A. Evaluation of the biomechanical behavior of maxillary central incisors restored by means of endocrowns compared to a natural tooth: a3D static linear finite elements analysis. Dent Mater.Dent Mater. 2006 Nov;22(11):1035-44. doi: 10.1016/.jdental.2005.11.034.

22. Bankoğlu Güngör M, Turhan Bal B, YilmazH, Aydin C, Karakoca Nemli S. Fracture strength of CAD/CAM fabricated lithium disilicate and resin nano ceramic restorations used for endodontically treated teeth. Dent Mater J. 2017 Mar 31;36(2):135-141. doi: 10.4012/dmj.2016-017. Epub 2017 Jan 20.

23. JA Sorensen and Engelman MJ, Ferrule design and fracture resistance of endodontically treated teeth. J Prosthet Dent. 1990.63(5):529-36. doi: 10.1016/0022-3913(90)90070-s

\section{Kamal Ebeid}

